\title{
Dialogues, dilemmas, and disclosures: genomic research and incidental findings
}

\author{
Lynn W. Bush, PhD, MA ${ }^{1}$ and Karen H. Rothenberg, JD, MPA ${ }^{2,3}$
}

As the evolution of next-generation sequencing into clinical research and practice progresses exponentially, so too will the discovery of incidental findings and ethical complexities accelerate. ${ }^{1,2}$ Controversial issues abound-such as determining whether, what, to whom, and how much genomic information should be disclosed to individual participants and their families. ${ }^{3,4}$ We believe that the research and bioethical communities need to engage in further dialogue, reflecting on these unresolved dilemmas to enrich the policy process.

To illuminate some of the personal and familial challenges surrounding the reporting of genomic findings, we composed It's So Complicated! (Supplementary Material online)- the sequel to It's Not That Simple! highlighting the informed consent process in our series of original dramatic vignettes designed to foster understanding of the ethical, psychological, legal, and social implications of genomic research. ${ }^{6}$ Feedback from stagings of Complicated (selections below) at the 2011 American Society for Bioethics and Humanities conference, the National Human Genome Research Institute, and universities in the United States and Australia parallel experiences with Not Simple - supporting this creative approach as a vehicle to enhance the appreciation for the complexity of sharing next-generation sequencing results.

It's So Complicated! brings to life the dialogues and dilemmas elicited by disclosing incidental findings through the lens of our recurring characters, Dr Hardy and the Friedman family-a mother, her 19-year-old son and 16-year-old daughter (both symptomatic with an autosomal recessive disorder), and Sam, their unaffected 9-year-old sibling-as they return to the geneticist after participating in genomic research. Along with exploring reactions toward results generated from the genomic study, the vignette illustrates the inherent tensions of the researcher/ clinician sharing findings with family members spanning generations, each with different values and affective responses.

The psychological, economic, and social risks of revealing genomic information that is even suggestive of disease to healthy participants must be carefully weighed against medical benefits. Although the lengthy consent form language subtly alludes to the possibility of learning secondary results, for many individuals it is as if the potential for discovering incidentals with whole exome/genome sequencing is highly remote. The element of surprise can be emotionally unsettling, particularly when neither families nor professionals fully anticipate the range of findings that will be routinely discovered upon the application of this powerful technology. Further complicating the discovery of incidental findings, it will often be the case that the original question for which genomic study was indicated may go unanswered:

DR. HARDY: Well, Amy, as for Bobby and your disorder, unfortunately nothing conclusive was uncovered...[however] we learned several things that I must discuss with some of you...findings unrelated to what we were looking for.

AMY: $\quad$ Huh? How can you find something if you weren't looking for it?...

MOM: What do you mean learn my results-I'm not sick!...Am I ?

Neither the researcher nor the participants can predict who will bear the burden and distress from the return of unanticipated findings. Implications need to be considered for individuals who previously identified themselves as healthy as well as those defined by their genetic condition. Moreover, there is little consensus regarding under what circumstances, if any, a consent form's request "not to know" may go unhonored:

DR HARDY: You mentioned last visit that you thought the stress...was making you forgetful... I'd like to recommend.... a neurologist.... There were certain findings...that hint at the possibility... and only a possibility...of a susceptibility...to something... and we want to check it out more clearly....

MOM: $\quad$ You're not implying that I'm going to go senile when I am 80 years old.... I told you I don't want to know that stuff... Alzheimer's is for old people. I'll worry about that when I get old. (exits)

DR HARDY: (to self): Assuming the CLIA test result confirms my finding, at least it will be the neurologist having to tell her she very likely has early-onset AD.

${ }^{1}$ Division of Clinical Genetics, Department of Pediatrics, Columbia University, New York, New York, USA; ${ }^{2}$ University of Maryland Francis King Carey School of Law, Baltimore, Maryland, USA; ${ }^{3}$ National Human Genome Research Institute and Department of Bioethics, Clinical Center, National Institutes of Health, Bethesda, Maryland, USA. Correspondence: Lynn W. Bush (lwb25@columbia.edu) 
The judgment regarding the disclosure of secondary results attained in genomic research remains controversial, and the need to clarify definitions such as variable penetrance and susceptibility is essential. There is great debate as to what revelations constitute urgency for disclosure and who should decide, as well as what findings are deemed clinically relevant, actionable, or predictable. Caution is also advised to avoid misinterpretation of susceptibility with a diagnosis of disease, especially when it is low risk.

DR HARDY: We found some....extra.....concerns..... The genome analysis shows that you carry the BRCA mutation....that doesn't necessarily mean you'll get breast cancer; it only indicates a susceptibility....the possibility for getting a disease. Indeed, your risk is quite low, only about $6 \%$ lifetime risk for breast cancer.....

BOBBY: I think you confused my results with Amy's or Mom's-that's a girl's disease.... Do Amy and Sam have breast cancer too? And Mom?

DR HARDY: First off, please let me be clear that I am not saying you have breast cancer. Only that you carry the genetic mutation associated with the possibility for developing the disease. We call that higher risk; not definitely getting the disease.....

BOBBY: (blurts to Mom) I have breast cancer!!!

DR HARDY: Please remember you don't have breast cancer now and might never even get it. It's only a potential future possibility.... a slight future possibility.

MOM: Oh my, is this some nightmare? We came here for you to tell us results that can help my kids' disease, and now you're telling Bobby he'll die from breast cancer instead?

Next-generation sequencing raises challenges when otherwise healthy children are faced with findings that threaten their identity and raise novel concerns about their future. ${ }^{8}$ The age range of the Friedmans highlights the additional responsibility required when considering sharing genomic information attained from families that include minors. As investigations involving children and adolescents engender even more complex ethical and psychological challenges, ${ }^{9}$ the need for heightened sensitivity by professionals becomes magnified, as does the unsettling nature for researchers. Differential approaches must be weighed not only to consider whether, but to whom, results may be disclosed: ${ }^{10}$

DR HARDY: I need to discuss something else with you... about Sam...about something else that we found in the genomic testing...related to her heart.
MOM: $\quad$ You must be mistaken...she's a really good athlete...on our Y's swim team....

DR HARDY: There's a condition called long QT syndrome...we can't perfectly predict when or which patients with the genetic predisposition... will have an arrhythmia associated with sudden cardiac arrest. So I need to share the seriousness of this with Sam and tell her we very strongly recommend that competitive athletics be forsaken.

MOM: $\quad$ Oh no, you can't tell her anything is wrong.... And anyway, remember you told me these tests aren't certain!

DR HARDY: I must inform her so she'll give up competitive sports...especially competitive swimming. (gets Sam and explains)....

SAM: (sobbing) But you're telling me I can't do what I do best....

MOM: I can't believe this is happening.... Sam was my healthy kid this morning....

DR HARDY: (reflective) I am so sorry.... it's so complicated!

Based on our experiences, the characters portrayed in the vignette highlight the complexity of emotions, reactions, and implications of disclosure of genomic information to family members spanning generations. As one physician witnessing the play at the 2011 American Society for Bioethics and Humanities conference, "Medicine is complicated, and the family is under psychological stress which impedes them from hearing and integrating the information."

In fact, interprofessional groups who played the characters expressed similar thoughts to those of the audience regardless of their geographical home or discipline. For example, a bioethicist portraying the role of the doctor wrote that this vignette "drew me into the head of Dr. Hardy to appreciate the challenge he was facing in attempting to disclose the incidental findings to the different family members. Reading his lines evoked his nervousness in me, which allowed me to convey the awkwardness of the situation." A physician playing Sam noted, "I saw how the doctor here was also in distress, with a lot of uncertainty regarding the incidental finding of this 9-year-old child, as he tries to explain that he really doesn't know what the consequences will be; this uncertainty is not well perceived by the family for we cannot talk of outcome but just make approximations."

The receptivity to exploring these complex ethical dilemmas through creative avenues such as dramatic vignettes suggests value in bringing to life the challenges faced by participants and professionals in order to enhance the discourse and policy process. As one member of the audience remarked, "By having the play highlight just how jarring it can be for a familyand a doctor-it really showed us how essential it is that we decide ahead of time what incidental findings actually should be reported." 


\section{SUPPLEMENTARY MATERIAL}

Supplementary material is linked to the online version of the paper at http://www.nature.com/gim

\section{ACKNOWLEDGMENTS}

We acknowledge the support of our colleagues at Columbia University, the National Human Genome Research Institute, National Institutes of Health Clinical Center, the University of Maryland Francis King Carey School of Law, the American Society for Bioethics and Humanities, and several Australian academic centers. We are also grateful to the physician-geneticists and genetic counselors who generously advised us, as well as to all the actor and audience participants.

\section{DISCLOSURE}

The authors declare no conflict of interest.

\section{REFERENCES}

1. Fabsitz RR, McGuire A, Sharp RR, et al. Ethical and practical guidelines for reporting genetic research results to study participants: updated guidelines from a National Heart, Lung and Blood Institute working group. Circ Cardiovasc Genet 2010;3:574-580

2. Wolf SM, Paradise J, Nelson CA, et al, eds. Incidental findings in human subjects research: from imaging to genomics. J Law Med Ethics 2008;36:211-383.

3. Bredenoord AL, Onland-Moret NC, Van Delden JJ. Feedback of individual genetic results to research participants: in favor of a qualified disclosure policy. Hum Mutat 2011;32:861-867.

4. Kohane IS, Masys DR, Altman RB. The incidentalome: a threat to genomic medicine. JAMA 2006; 296:212-215.

5. Rothenberg KH, Bush LW. It's not that simple!: genomic research \& the informed consent process. http://www.nature.com/gim/journal/v14/n2 suppinfo/gim201147s1.htm Genet Med 2012;14, supplementary material online.

6. Oliver JM, McGuire AL. Exploring the ELSI universe: critical issues in the evolution of human genomic research. Genome Med 2011; 3:38.

7. Rothenberg KH, Bush LW. Genes \& plays: bringing ELSI issues to life. Genet Med 2012;14:273-276.

8. Davis DS. Genetic dilemmas and the child's right to an open future. Hastings Cent Rep 1997;27:7-15.

9. Wilfond BS, Carpenter KJ. Incidental findings in pediatric research. J LaW Med Ethics 2008;36:332-340.

10. Hens K, Nys H, Cassiman JJ, et al. The return of individual research findings in paediatric genetic research. J Med Ethics 2010;37:179-183. 